\title{
Pembelajaran Terpadu Dalam Perspektif K.H. Ahmad Dahlan
}

\author{
Tukinah \\ Tukinah90@gmail.com \\ Universitas Ahmad Dahlan (UAD) Yogyakarta \\ Pera Ika Widayanti \\ peraika163@gmail.com \\ Universitas Ahmad Dahlan (UAD) Yogyakarta
}

\begin{abstract}
K.H. Ahmad Dahlan compiled Islamic education institutions in Indonesia which involved several factors, one of which was due to $\mathrm{K}$. $\mathrm{H}$. Ahmad Dahlan's concerns against indigenous Muslims, facilitating religious science education and general science. The purpose of this study was to study K. H. Ahmad Dahlan's educational concepts and question K. H. Ahmad Dahlan's educational philosophy. This research method is literature study (library research). The results of this study discuss the concept of K. H. Ahmad Dahlan's education, namely the integration of science and religion, the integration of religious science and general science, and freedom of thought. Furthermore K. H. Ahmad Dahlan's educational philosophy is the first, the highest knowledge can be achieved through common sense and istiqamah towards the truth of reason and based on a pure heart. Second, reason is a basic human need. Third, the science of mantiq or logic is the highest education for humans which can only help if humans escape God's guidance.
\end{abstract}

Keywords: philosophy; thought; education

Abstrak: K.H. Ahmad Dahlan mendirikan lembaga pendidikan Islam Indonesia dipengaruhi oleh beberapa faktor salah satunya karena keprihatinan K. H. Ahmad Dahlan terhadap umat Islam pribumi, kesenjangan pendidikan ilmu agama dan ilmu umum. Tujuan penelitian ini untuk mengetahui konsep pemikiran pendidikan K. H. Ahmad Dahlan dan memahami filosofi pendidikan K. H. Ahmad Dahlan. Metode

Belajea: Jurnal Pendidikan Islam Vol. 5, No 01, 2020; 151-160 p-ISSN 2548-3390; e-ISSN 2548-3404, DOI:10.29240/belajea.v5 available online at:http://journal.staincurup.ac.id/indek.php/belajea 
penelitian ini adalah studi pustaka (library research). Hasil penelitian ini menyebutkan bahwa konsep pemikiran pendidikan K. H. Ahmad Dahlan yaitu integrasi ilmu dan agama, integrasi ilmu agama dan ilmu umum, dan kebebasan berfikir. Selanjutnya filosofi pendidikan K. H. Ahmad Dahlan adalah pertama, pengetahuan tertinggi dapat diraih melalui akal sehat dan istiqamah terhadap kebenaran akal dan didasari hati yang suci. Kedua, akal adalah kebutuhan dasar hidup manusia. Ketiga, ilmu mantiq atau logika adalah pendidikan tertinggi bagi akal manusia yang hanya dapat dicapai jika manusia menyerah kepada petunjuk Allah.

Kata Kunci: filosofi; pemikiran; pendidikan

\section{Pendahuluan}

K.H. Ahmad Dahlan mendirikan lembaga pendidikan Islam di Indonesia salah satunya karena pendidikan di Indonesia pada masa itu masih kurang, terutama untuk pendidikan agama. Pemerintah tidak mungkin mendirikan lembaga pendidikan di seluruh pelosok nusantara, dan lembaga pendidikan Islam yang didirikan oleh K.H. Ahmad Dahlan sangat membantu pemerintah ${ }^{1}$. Dengan adanya lembaga pendidikan yang didirikan oleh K.H. Ahmad Dahlan, masyarakat Indonesia khususnya Yogyakarta mulai tertarik dengan dunia pendidikan.

Selanjutnya pada tanggal 18 November 1912 Ahmad Dahlan mendirikan organisasi Muhammadiyah terutama untuk mendalami agama Islam dikalangan anggota sendiri dan menyebarkan agama Islam di luar anggota inti. Ahmad Dahlan menyebarluaskan Muhammadiyah Tabligh dan relasi-relasi dagang yang dimilikinya ke berbagai kota. Muhammadiyah mendapatkan sambutan besar di berbagai kota besar di Indonesia, sehingga ulama-ulama dari berbagai daerah berdatangan kepadanya untuk memberi dukungan kepada Muhammadiyah. Atas dukungan tersebut, pada tanggal 7 Mei 1912 Ahmad Dahlan mengajukan permohonan ke pemerintah Hindia Belanda untuk mendirikan cabang Muhammadiyah di seluruh Indonesia. Permohonan tersebut dikabulkam oleh pemerintah Hindia Belanda pada tanggal 2 September 1921.

${ }^{1}$ Arofah, Siti, dan Maarif Jamu'in. 2015. "Gagasan Dasar dan Pemikiran Pedidikan Islam K.H Ahmad Dalan.” Jurnal Tajdida 13 (2): 116. 
K.H. Ahmad Dahlan merupakan tokoh nasional yang mempunyai tipe man of action artinya orang yang lebih mengutamakan praktek daripada teori ${ }^{2}$. Cita-cita pendidikan yang digagas Ahmad Dahlan adalah lahirnya manusiamanusia yang mampu tampil sebagai "ulama-intelek" atau "intelektual-ulama" yaitu seorang muslim yang mempunyai keteguhan iman dan ilmu yang luas, kuat jasmani dan rohani. Oleh karena itu, ide pendidikan yang digagas Ahmad Dahlan adalah menyelamatkan umat Islam dari cara berfikir statis menuju pemikiran yang dinamis, kreatif dan inovatif. Salah satu jalan yang utama untuk mencapai tujuan tersebut adalah melalui pendidikan dan pengelolaan pendidikan Islam secara modern dan professional, sehingga pendidikan yang dilaksanakan mampu memenuhi peserta didik sesuai dengan tuntutan zamannya. Gagasan pemikiran Ahmad Dahlan dilatarbelakangi oleh beberapa faktor, diantaranya, keprihatinan terhadap umat islam pribumi, kesenjangan pendidikan ilmu agama dan ilmu umum, pertarungan melawan Kristen ${ }^{3}$. Olehkarena itu, Ahmad Dahlan sangat tertarik sekali untuk mengubah pola berfikir masyarakat pribumi agar tidak terkungkung dengan keadaan saat itu.

Hal tersebut berdampak pada kualitas pendidikan yang ada di Indonesia, yaitu pendidikan secara umum mengalami keterbengkalaian para murid di sekolah hanya di suruh melakukan gerak badan, baris-berbaris, kerja bakti (romusha), bernyanyi dan lain sebagainya. Pada abad ke 20 muncul banyak ide pembaharuan pendidikan Islam di Indonesia dikarenakan mayoritas orang mulai tidak puas dengan sistem pendidikan yang berlaku saat itu. Bagian yang perlu diperbaharui diantaranya materi, metode pembelajaran, manajemen dan administrasi pendidikan. Pada saat itu ada tokoh-tokoh pembaharu pemikiran Islam diantaranya Jamaludin al-Afghani, Muhammad Abduh, Muhammad Rasyid Ridha, Rifa' al-Thathawi, Sayyid Ahmad Khan dan sebagainya. Sehingga memberikan pengaruh besar bagi tokoh-tokoh pemikir Islam di Indonesia untuk melakukan pembaharuan (Ni'mah 2014a). ${ }^{4}$ Pembaharuan pendidikan tidaklah

\footnotetext{
${ }^{2}$ Hamsyah, Amir. 1968a. Pembaharuan Pendidikan dan Pengajaran Islam. Malang: UP Kenmutia: 70

${ }^{3}$ Arofah, Siti, dan Maarif Jamu'in. 2015. “Gagasan Dasar dan Pemikiran Pedidikan Islam K.H Ahmad Dalan.” Jurnal Tajdida 13 (2): 119.

${ }^{4}$ Ni'mah, Zetty Azizatun. 2014a. "Pemikiran Pendidikan Islam Perspektif KH. Ahmad Dahlan (1869-1923 M) dan KH. Hasyim Asy'ari (1871-1947 M) : Study Komparatif dalam Konsep Pembaruan Pendidikan Islam di Indonesia.” Didaktika Religia 2 (1): 135-74.
} 
semudah membalikkan telapak tangan, namun penuh dengan kerja keras yang patut kita hormati dan kita hargai sampai saat ini.

Diantara banyaknya pemikir islam di Indonesia, salah satunya adalah $\mathrm{K}$. H. Ahmad Dahlan, beliau adalah seorang ulama yang mempunyai keberanian dan tekad yang sangat kuat untuk melakukan pembaharuan terhadap pendidikan yang ada di Indonesia. Salah satu usaha Ahmad Dahlan dalam memperbaiki pendidikan islam ialah dengan mendirikan lembaga pendidikan Muhammadiyah, yang di dalamnya mempelajari ilmu agama sebagai pelajaran wajib dan ilmu umum sebagai penunjang. Sehingga rakyat Indonesia menikmati pendidikan yang jauh lebih baik daripada sebelumnya.

Berdasarkan pemaparan di atas maka rumusan masalah dalam penelitian ini adalah pertama, bagaimana konsep dan pemikiran pendidikan Islam menurut K. H. Ahmad Dahlan. Kedua, bagaimana filosofi pendidikan K. H. Ahmad Dahlan. Oleh karena itu, dalam penelitian ini ditawarkan sebuah solusi tentang bagaimana pembelajaran terpadu dalam perspektif K. H. Ahmad Dahlan. Berdasarkan uraian di atas, maka tujuan pembahasan ini adalah untuk mengetahui konsep pemikiran dan filosofi pendidikan Islam menurut $\mathrm{K}$. $\mathrm{H}$. Ahmad Dahlan.

\section{Pembahasan}

Muhammadiyah diakui sebagai organisasi Islam yang paling menonjol dalam amal usaha pendidikan. Pendidikan bahkan menjadi ciri penting bahkan melekat pada gerakan Muhammadiyah. Lembaga pendidikan dari tingkat dasar hingga perguruan tinggi dimiliki Muhammadiyah, termasuk taman kanak-kanak Aisyiyah Busthanul Athfal yang terbesar di seluruh tanah air. Ciri penting dan merupakan kepeloporan Muhammadiyah dan lembaga pendidikan yang dirintis dan dikembangkannya adalah sistem pendidikan Islam moderen yang terpadu atau holistik. Artinya pendidikan Islam yang diperkenalkan oleh Muhammadiyah memadukan pendidikan agama dan pendidikan umum dalam satu kesatuan sistem, baik dalam bentuk sekolah atau perguruan umum atau madrasah dan pondok pesantren.

Pendidikan berkemajuan berlandaskan agama dan kehidupan sosial yang sangat menghargai kecerdasan (akal/inteligen) sebagai piranti untuk memahami pesan-pesan agama dan anatomi kehidupan sosial, dan bertujuan untuk menumbuhkan akal (kecerdasan) sehingga seluruh kepribadiannya bertumbuh 
(growth) dan menggerakkan kemajuan sosial (progress). Pendidikan jika dilandaskan pada agama dan disinergikan dengan sosial maka akan menciptakan sebuah pendidikan yang sangat baik.

Menurut Ahmad Dahlan tujuan pendidikan Islam diarahkan pada usaha untuk membentuk manusia yang beriman, berakhlak mulia, memahami ajaran agama Islam, berpengetahuan luas dan kapasitas intelektual yang dapat diaplikasikan di dalam kehidupan sehari-hari. Untuk mencapai tujuan tersebut Ahmad Dahlan menyatakan bahwa pendidikan Islam harus dibarengi dengan integrasi ilmu dan amal, integrasi ilmu pengetahuan umum dan agama, kebebasan berpikir dan pembentukan karakter, agar peserta didik dapat berkembang sesuai dengan intelektualitas dan spiritualitasnya.

1. Integrasi Ilmu dan Agama

Konsep pendidikan yang mengintegrasikan antara ilmu dan amal terlihat dalam pendidikan organisasi Muhammadiyah yang didirikannya. Contohnya, ketika Ahmad Dahlan mengajarkan surat al-Maun ayat 1-7. Ahmad Dahlan terus menerus mengajarkan surat al-Maun kepada peserta didiknya, agar mereka hafal dan memahami arti selanjutnya mengimplementasikannya dalam kehidupan sehari-hari.

Disamping itu Ahmad Dahlan mendirikan organisasi Aisyiyah yaitu organisasi yang beranggotakan khusus wanita, kemudian berkembang mendirikan panti asuhan yatim khusus putri yang dibekali dengan ilmu agama dan ilmu umum. Melalui organisasi Aisyiyah melatih seorang wanita untuk memiliki kepedulian terhadap sesama muslim.

Berdasarkan contoh di atas Ahmad Dahlan menginspirasi terhadap peserta didik agar terbiasa menjalani amalnya sejak usia dini. Selain itu, pembentukan kepribadian sangat penting bagi peserta didik dalam rangka mencapai keselamatan dunia dan akhirat. Sebagaimana sabda nabi Muhammad Saw yang artinya "bekerjalah untuk duniamu seolah engkau akan hidup selamanya dan beramalah untuk akhiratmu seakan engkau akan mati hari esok". ${ }^{6}$ Dengan adanya kesinambungan

${ }^{5}$ Ali, Mohamad, Sodiq A. Kuntoro, dan Sutrisno. 2016. "Pendidikan Berkemajuan : Refleksi Praksis Pendidikan K.H. Ahmad Dahlan.” Jurnal Pembangunan Pendidikan: Findasi dan Aplikasi 4 (1): 56.

${ }^{6}$ Ridjaluddin F. N. 2009. Filsafat Pendidikan Islam. Jakarta Selatan: Pustaka Kajian Islam. 12. 
antara dunia dan akhirat maka seseorang tidak akan merasa terus menerus kekurangan, ia akan selalu bersyukur dengan apa yang sudah dimilikinya.

2. Integrasi Ilmu Agama dan Ilmu Umum

Menurut Ahmad Dahlan, untuk mencapai tujuan ini maka perlu proses pendidikan yang bersifat integral. Artinya, peserta didik harus memiliki empat kecerdasan yaitu kecerdasan intelektual, spiritual, emosional dan sosial. Berkaitan dengan implementasi tujuan ini, ada beberapa metode yang perlu diterapkan, yaitu sebagai berikut ${ }^{7}$ :

a. Metode pembiasaan

Pembiasaan adalah seuatu yang dilakukan secara sengaja dan berulang-ulang agar sesuatu itu menjadi kebiasaan. Metode pembiasaan ini sebagaimana falsafah orang Jawa Iso amargo soko kulino artinya orang itu bisa karena terbiasa. Oleh karena itu, pembiasaan ini penting bagi peserta didik agar memiliki moral yang baik.

b. Metode keteladanan

Keteladanan adalah pembelajaran moralitas di mana pendidik terlibat aktif dalam nilai ajaran yang disampaikan. Artinya, ketika pendidik mengajarkan peserta didik agar berperilaku baik, maka pendidik harus mencontohkan perilaku baik itu dalam kehidupan kesehariannya.

c. Metode memberi nasehat

Abdurarahman an-nahlawi sebagaimana dikutip oleh Hery Noer Aly nasehat adalah penjelasan kebenaran dan kemaslahatan dengan tujuan menghindarkan orang yang dinasehati dari bahaya serta menunjukkannya ke jalan yang mendatangkan kebahagiaan dan manfaat.

d. Metode Motivasi dan Intimidasi

Motivasi dan intimidasi dalam bahasa Arab disebut dengan uslub al-targhib wa al-tarhdib atau metode targhib dan tarhib. Metode ini sangat efektif apabila penyampaiannya menarik dan meyakinkan peserta didika. Oleh karena itu, pendidik hendaknya dapat menggunakan metode ini.

3. Kebebasan Berpikir

${ }^{7}$ Abudin. 2005. Tokoh-tokoh Pembaharuan Pendidikan di Indonesia. Jakarta : PT. Raja Grafindo Persada. 10 
Menurut Ahmad Dahlan, menjadi manusia menuju kebebasan berpikir memang berarti progresif dan dinamis, tetapi seharusnya kebebasan itu bersifat relatif, terikat oleh ruang dan waktu, karena yang modern secara mutlak hanyalah Allah dan tetap berdasarkan kaidah-kaidah ajaran Islam ${ }^{8}$. Jika seserang tidak mempunyai kebebasan dalam berfikir, maka ia tidak akan bisa mengembangakan bakatnya dan hanya berada dalam kondisi yang menjenuhkan.

Kebebasan berpikir berarti mengembangkan rasio atau penalaran yang dimilikinya sehingga mampu mengembangkan, menjelaskan dan menjabarkan sendiri teori-teori. Di samping itu, mampu menghindarkan dari mengikuti pandangan orang lain tanpa mengetahui alasannya (taqlid). Cara Ahmad Dahlan mengajar selalu memberikan kesempatan kepada peserta didik berpikir dengan konteks kekinian, tetapi tidak menyimpang dari ajaranajaran Islam. Hal ini bertujuan agar peserta didik mempunyai wawasan yang luas dan tidak hanya berpikir secara monoton. ${ }^{9}$ Namun, dalam berfikir haruslah ada batas ruangnya, Karena jika tidak membatasi maka ia akan mengalami kesulitan sendiri, kuncinya adalah tetap berpegang pada ajaran dan ketetapan hokum islam.

Pendidikan di Indonesia berada pada kondisi yang sangat memprihatinkan saat zaman penjajahan kolonial belanda. Dimana lembaga Pendidikan mendapat perlawanan yang sangat kuat terhadap lembaga yang didirikan oleh pemerintah kolonial belanda. Di bawah tantangan sistem Pendidikan yang demikian ini, persyrikatan Muhammadiyah yang didirikan oleh K.H. Ahmad Dahlan menjawabnya dengan mendirikan sekolah yang serupa tetapi tidak sama kurikulumnya. Kurikulum Sekolah persyrikatan Muhammadiyah berbeda dengan kurikulum Sekolah yang didirikan oleh pemerintah colonial belanda. Perbedaanya, disekolah persyrikatan Muhmmadiyah ada mata pelajaran al-quran. ${ }^{10}$ Naim menyatakan bahwa KH. Ahmad Dahlan menginginkan pengelolaan pendidikan islam secara modern

\footnotetext{
${ }^{8}$ Suharto, Toto. 2011. Filsafat Pendidikan Islam. Yogyakarta : Ar-Ruzz Media. 107
}

9 Sucipto, Hery. 2010. K.H. Ahmad Dahlan Sang Pencerah dan Pendiri Muhammadiyah. Jakarta : Media Utama.56

${ }^{10}$ Lenggono, Wahyu. 2018. "Lembaga Pendidikan Muhammadiyah (Telaah Pemikiran K.H. Ahmad Dahlan Tentang Pembaruan Pendidikan Islam di Indonesia)." Jurnal Islamadina 19 (1): 43-62. 
dan profesional, sehingga pendidikan yang dilaksanakan mampu memenuhi kebutuhan peserta didik menghadapi dinamika zamannya.

Salah satu usahanya dalam memajukan pendidikan Islam adalah memperbaharui sistem pendidikan yang dualistis, yaitu antara ilmu agama dan ilmu pengetahuan umum. Ia harus menyatukan sistem pendidikan Barat yang lebih mengutamakan dan mengembangkan aspek intelektual, dan sistem pendidikan Islam yang kurang mengembangkan aspek intelektual (Setiawan 2018, 7). (Ali 2016, 49) menyatakan dalam tulisannya, bahwa dalam pandangan $\mathrm{KH}$ Ahmad Dahlan, tujuan pendidikan: dadiyo kyai sing kemajuan, lan aja kesel-kesel anggonmu nyambut gawe kanggo Muhammadiyah 17, terjemahan dalam bahasa Indonesia kurang lebih: jadilah ulama yang berkemajuan, dan tidak kenal lelah bekerja/beramal bagi Muhammadiyah. Kata-kata Kyai Dahlan tersebut dapat diinterpretasikan bahwa tujuan pendidikan Muhammadiyah menurutnya adalah untuk mewujudkan dan menumbuhkan manusia religius, orang Islam yang menguasai "ilmu-ilmu agama" maupun "ilmu-ilmu umum" sekaligus di mana secara individual seluruh potensi/fitrahnya tumbuh optimal sehingga bisa menjadi pribadi yang cerdas (inteligen), yaitu pribadi yang bersedia berjuang atau bekerja untuk memecahkan masalah-masalah sosialkemasyarakatan dan menggerakkan ke arah kemajuan (progress). Dengan demikian, secara singkat kyai berkemajuan adalah ulama yang bersedia terlibat dan mampu memecahkan permasalahan sosial-kehidupan yang dihadapi masyarakat. Karena kebenaran agama maupun ilmu dalam pandangan kyai Dahlan harus diuji secara "pragmatis", yaitu kegunaan secara fungsional untuk memecahkan problematika kehidupan yang muncul silih berganti.

K.H. Ahmad Dahlan banyak mewariskan amal usaha bukan karya atau tulisan. Oleh karena itu, beliau banyak membangun sistem pendidikan. naskah terakhir beliau yang berjudul Tali Pengikat Hidup mengandung unsur eksplisit terhadap pencerahan akal dan suci melalui filsafat dan logika. Ada tiga kalimat kunci untuk mencapai penecarahan akal, yaitu $:^{11}$

${ }^{11}$ Hamsyah, Amir. 1968a. Pembaharuan Pendidikan dan Pengajaran Islam. Malang: UP Kenmutia. 5 
1) Pengetahuan tertinggi adalah kesatuan hidup yang dapat diraih melalui akal sehat dan istiqamah terhadap kebenaran akal dan didasari hati yang suci.

2) Akal adalah kebutuhan dasar hidup manusia

Ilmu mantiq atau logika adalah pendidikan tertinggi bagi akal manusia yang hanya dapat dicapai jika manusia menyerah kepada petunjuk Allah.

\section{Penutup}

Berdasarkan uraian di atas, kesimpulan penelitian ini adalah : Konsep pemikiran pendidikan menurut K.H Ahmad Dahlan adalah, adanya integrasi ilmu dan agama, integrasi ilmu agama dan ilmu umum, dan pembebasan berfikir. Selanjutnya adalah filosofi pendidikan K.H. Ahmad Dahlan adalah, pertama pengetahuan tertinggi dapat diraih melalui akal sehat dan istiqomah; kedua akal adalah kebutuhan dasar hidup manusia; ketiga ilmu mantiq atau logika adalah pendidikan tertinggi bagi akal manusia yang hanya dapat diraih jika manusia menyerah kepada petunjuk Allah.

\section{Bibliografy}

Ali, Mohamad. 2016. "Membedah tujuan pendidikan muhammadiyah." Jurnal Profetika 17 (1).

Ali, Mohamad, Sodiq A. Kuntoro, dan Sutrisno. 2016. "Pendidikan Berkemajuan: Refleksi Praksis Pendidikan K.H. Ahmad Dahlan.” Jurnal Pembangunan Pendidikan: Findasi dan Aplikasi 4 (1).

Arofah, Siti, dan Maarif Jamu'in. 2015. "Gagasan Dasar dan Pemikiran Pedidikan Islam K.H Ahmad Dalan.” Jurnal Tajdida 13 (2).

Hamsyah, Amir. 1968a. Pembaharuan Pendidikan dan Pengajaran Islam. Malang: UP Kenmutia.

. 1968b. Pembaharuan Pendidikan dan Pengajaran Islam. Malang: UP Kenmutia.

Lenggono, Wahyu. 2018. "Lembaga Pendidikan Muhammadiyah (Telaah Pemikiran K.H. Ahmad Dahlan Tentang Pembaruan Pendidikan Islam di 
160 | Belajea: Jurnal Pendidikan Islam, Vol. 5, No. 01, 2020

Indonesia)." Jurnal Islamadina 19 (1).

Nata, Abudin. 2005. Tokoh-tokoh Pembaharuan Pendidikan di Indonesia. Jakarta: PT. Raja Grafindo Persada.

Ni'mah, Zetty Azizatun. 2014a. "Pemikiran Pendidikan Islam Perspektif KH. Ahmad Dahlan (1869-1923 M) dan KH. Hasyim Asy'ari (1871-1947 M) : Study Komparatif dalam Konsep Pembaruan Pendidikan Islam di Indonesia." Didaktika Religia 2 (1)

_ 2014b. "Pemikiran Pendidikan Islam Perspektif KH. Ahmad Dahlan (1869 - 1923 M) dan KH. Hasyim Asy'ari (1871 - 1947 M) : Study Komparatif dalam Konsep Pembaruan Pendidikan Islam di Indonesia.” Didaktika Religia 2 (1)

Ridjaluddin F. N. 2009. Filsafat Pendidikan Islam. Jakarta Selatan: Pustaka Kajian Islam.

Setiawan, Iwan. 2018. "Islam dan Nasionalisme: Pandangan Pembaharu Pendidikan Islam Ahmad Dahlan dan Abdulwahab Khasbullah.” Jurnal: Hayula 2 (1)

Sucipto, Hery. 2010. K.H. Ahmad Dahlan Sang Pencerah dan Pendiri Muhammadiyah. Jakarta : Media Utama.

Suharto, Toto. 2011. Filsafat Pendidikan Islam. Yogyakarta : Ar-Ruzz Media. 